\title{
The Nova Scotian Institute of Science
}

- The Nova Scotian Institute of Science was formed in 1862 from the Halifax Mechanics Institute (1831-1860) and the Halifax Literary and Scientific Society (1839-1862) making it one of the oldest learned societies in Canada.

- Among the Institute's roles are the stimulation of scientific research and provision of scientific information to scientists and the general public through meetings and publication of the Proceedings of the Nova Scotian Institute of Science. The Institute provides scientists, technologists, educators and administrators with an opportunity to communicate with each other and to the community through public lectures, panel discussions, its Proceedings and the Internet.

- The Institute has a library, established in 1864, now housed in the Killam Library at Dalhousie University; it has a number of periodicals not available elsewhere in Canada.

- $\quad$ Prominent members of the scientific community are invited to address the Institute at a series of regular meetings held on the first Monday of each month from October to May. The lectures and panel discussions are free and open to the public; the topics are of broad interest. The meetings take place usually at the Nova Scotia Museum of Natural History, 1747 Summer Street, Halifax at 7:30 PM. For topics, meeting locations and more information on the Institute please consult the NSIS website:

http://www.chebucto.ns.ca/Science/NSIS

- Membership in the Institute is open to anyone with an interest in science. Information on joining can be obtained from the NSIS website and Council members.

2006-2007

Council Executive

President:

Vice-President:

Past President:

Secretary:

Treasurer:

Librarian:

Editor:
Stuart Grossert

Mary Jane O'Halloran

Carolyn Bird

Shannon Scott-Tibbetts/

Linda Marks

Stephen Ewart

Sharon Longard

James Stewart

\section{Councillors}

Ken Adams

(Writing Competition Coordinator)

John Cordes (Webmaster)

David Jakeman

Sandra Nowlan (Publicity)

David Richardson

Evelyn Soo

Douglas Strongman

Sean Tibbetts (Mentorship)

\section{Representatives}

David Christianson, NS Museum

Brad Tucker/Karen Dobbin, Discovery Centre

Alexis Paton, Student, Dalhousie Univ

Joseph Poissant, Student, St Mary's Univ

\section{Proceedings of the Nova Scotian Institute of Science}

Sponsored by the Nova Scotian Institute of Science and supported in part by a grant from the Nova Scotia Museum, the Proceedings produces one or more issues per year and will consider for publication original articles principally, but not exclusively, in the areas of natural and engineering sciences as well as papers emanating from studies in the health professions. Papers that develop new scientific theories based on scientific principles and/or analysis of data particular to Nova Scotia or the Atlantic Provinces are especially encouraged. 